\title{
Biochar Sebagai Penyimpan Karbon, Perbaikan Sifat Tanah, dan Mencegah Pemanasan Global : Tinjauan
}

\section{Biochar As Carbon Sequestration and Soil Amendment, to Avoid Global Warming: A Review}

\author{
Rakhman Sarwono ${ }^{1}$ \\ ${ }^{1}$ Pusat Penelitian Kimia - Lembaga Ilmu Pengetahuan Indonesia \\ Corresponding author: rakhman.sarwono@ lipi.go.id
}

\begin{tabular}{l} 
A R T I C L E I N F O \\
\hline Article history \\
Received date : 8 July 2015 \\
Revised date : 4 May 2016 \\
Accepted date :10 June 2016 \\
Available online at: \\
http://kimia.lipi.go.id/inajac/index.php
\end{tabular}

Kata kunci:

GRK, biochar, penyimpanan karbon, pemanasan global, perubahan iklim, $\mathrm{CO}_{2}$

Keywords:

GHG, biochar, carbon sink, global warming, climate change, $\mathrm{CO}_{2}$

\begin{abstract}
Abstrak
Terjadinya pemanasan global disebabkan karena makin tingginya konsentrasi gas rumah kaca (GRK) di atmosfir. Pemanasan global akan memberi dampak yang buruk terhadap kehidupan mahluk hidup di bumi ini. GRK yang sangat berpengaruh terhadap naiknya temperatur atmosfir bumi adalah gas $\mathrm{CO}_{2}$ [karbon dioksida], NOx, metan dan freon. Salah satu GRK yang menjadi perhatian adalah gas $\mathrm{CO}_{2}$, karena gas $\mathrm{CO}_{2}$ kebanyakan dari kegiatan manusia seperti pembakaran bahan bakar fossil yang jumlahnya selalu meningkat setiap tahunnya. Sejak revolusi industri sampai sekarang terjadi akumulasi gas $\mathrm{CO}_{2}$ di atmosfir yang semakin besar, dengan konsentrasi $\mathrm{CO}_{2}$ sebesar $390 \mathrm{ppm}$. Hal ini ditengarai sebagai penyebab terjadinya pemanasan global dan perubahan iklim. Untuk menahan laju penambahan konsentrasi gas $\mathrm{CO}_{2}$ di atmosfir perlu adanya cara untuk mengurangi karbon di atmosfir. Salah satu cara untuk mengurangi karbon dioksida $\mathrm{CO}_{2}$ di atmosfir adalah dengan mengkonversi biomasa menjadi biochar dan selanjutnya biochar dimasukkan kedalam tanah sebagai pemuliaan tanah agar kelestarian pertanian bisa berlanjut. Bila biochar bisa diproduksi dalam jumlah yang besar yang setara dengan jumlah karbon yang masuk ke atmosfir, maka akan terjadi keseimbangan antara gas $\mathrm{CO}_{2}$ yang masuk dan keluar atmosfir. Penyimpanan karbon sebesar 1 gigaton pertahun selama 40 tahun akan menghambat penambahan konsentrasi gas $\mathrm{CO}_{2}$ di atmosfir. Sehingga laju penambahan gas rumah kaca bisa dicegah.
\end{abstract}

\begin{abstract}
Global warming is predicted to occur by increasing the concentration of green house gas [GHG] in the atmosphere. Global warming has negative impact to the living thing on earth. The accumulation of GHG increases of the atmospheric temperature. There are many different types of GHG gas such as $\mathrm{CO}_{2}$, NOx, methane, and freon. One of the most famous $\mathrm{GHG}$ is $\mathrm{CO}_{2}$, that is produced anthropogenic activities such as fossil fuel burning that quantity increases regularly every year. Since industrial revolution until now the $\mathrm{CO}_{2}$ gas concentration in atmosphere has been accumulated to about 390 ppm. Reducing of the $\mathrm{CO}_{2}$ concentration in atmosphere by sink down of the carbon $C$ as biochar is necessary. Conversion of biomass into biochar is a benign way how to slowdown the increasing concentration of $\mathrm{CO}_{2}$ in the atmosphere. The biochar can be used as soil amendment to support sustainable agriculture. The quantity of biochar produced must exeed the amount of carbon entering the atmosphere, therefore carbon balance in the atmospheric reservoir will be reached. Carbon sequestration in the amount of one gigatons per year in 40 years will maintain the $\mathrm{CO}_{2}$ concentration in the atmosphere. The decreasing amount of $\mathrm{CO}_{2}$ entering the atmosphere will reduce, global warming and hopefully climate change will not happened.
\end{abstract}

(C) 2016 Indonesian Journal of Applied Chemistry. This is an open access article under the CC BY-NC-SA license. 


\section{Pendahuluan}

Konsentrasi gas $\mathrm{CO}_{2}$ di atmosfir akan selalu meningkat karena lebih banyak gas $\mathrm{CO}_{2}$ yang dihasilkan dibandingkan dengan yang diserap. Hal ini akan menyebabkan meningkatnya konsentrasi gas $\mathrm{CO}_{2}$ di atmosfir yang akan mengakibatkan naiknya temperatur atmosfir bumi, yang menyebabkan terjadinya pemanasan global. Pemanasan global akan terus meningkat seiring dengan kenaikan konsentrasi GRK di atmosfir. Kenaikan temperatur satu abad yang lalu sebesar $1{ }^{\circ} \mathrm{C}$, namun World Meteorological Organisation (WMO) mencatat bahwa tahun 2015 merupakan tahun terpanas yang pernah terjadi. ${ }^{[1]}$ Ada yang memprediksi bahwa kenaikan temperatur bisa mencapai 0,3 sampai $4,8{ }^{\circ} \mathrm{C}$ pada akhir abad ini. ${ }^{[2]}$ Pemanasan global akan menyebabkan terjadinya perubahan iklim, mencairnya es di kutub utara maupun selatan yang menyebabkan kenaikan permukaan laut, musim hujan yang tidak teratur, bertambah lebar dan kuatnya bila terjadi angin rebut. ${ }^{[3]}$ Penemuan baru menunjukkan bahwa perubahan iklim bisa menyebabkan pergeseran sumbu putar bumi. ${ }^{[4]}$ Perubahan temperatur terhadap kenaikan konsentrasi $\mathrm{CO}_{2}$ di atmosfir ditunjukkan pada Gambar 1.

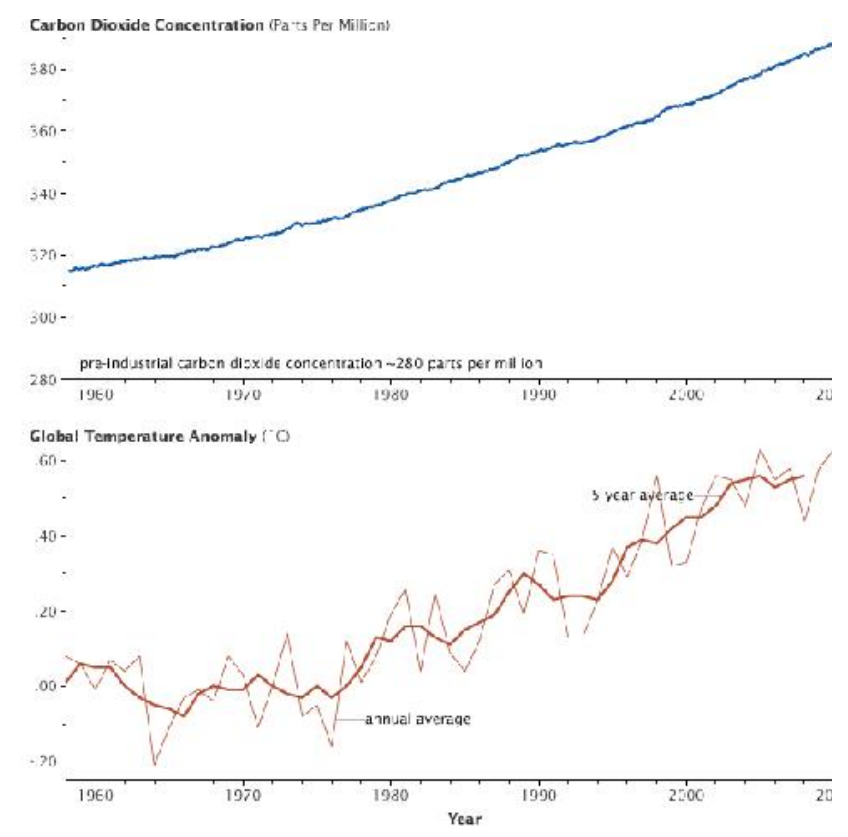

Gambar 1. Perubahan temperatur atmosfir terhadap konsentrasi gas $\mathrm{CO}_{2}{ }^{[5]}$
Atmosfir merupakan reservoirs gas $\mathrm{CO}_{2}$ di bumi. Atmosfir setidaknya menyimpan karbon sebanyak 720 gigaton. ${ }^{[6]}$ Kadar karbon dalam $\mathrm{CO}_{2}$ di atmosfir mempunyai peranan yang penting dalam perubahan temperatur di atmosfir. Konsentrasi gas $\mathrm{CO}_{2}$ di atmosfir sekitar $0,04 \%$ basis molar. Gas $\mathrm{CO}_{2}$ mempunyai kemampuan menyerap panas yang menyebabkan terjadinya efek gas rumah kaca. Pada tahun 1990-an, manusia menyumbang penambahan gas $\mathrm{CO}_{2}$ ke atmodfir sebesar $8.0 \mathrm{x}$ $10^{15}$ gram (gigaton atau $\mathrm{Pg}$ ) karbon, yang berasal dari pembakaran bahan bakar fossil sekitar 6,4 PgC/tahun, pembukaan lahan di daerah tropis sebesar $1,6 \mathrm{PgC}$ per tahun. Sedangkan gas $\mathrm{CO}_{2}$ yang terserap oleh lautan sebesar $28 \%$, terabsorbsi oleh tanah sebesar 32 $\%$, dan sisanya sekitar $40 \%$ menyebar di atmosfir. $^{[7]}$ Pada tahun 2009 konsentrasi $\mathrm{CO}_{2}$ secara global di atmosfir sebesar 390 ppm. ${ }^{[8]}$ Tingkat penambahan gas $\mathrm{CO}_{2}$ mengalami kenaikan menjadi 2,5\% pada tahun 2000 2009, dibandingkan $1 \%$ setiap tahunnya antara tahun $1990-1999^{[9]}$

Untuk mempertahankan konsentrasi gas $\mathrm{CO}_{2}$ di atmosfir agar tetap atau menurun maka perlu adanya sistem penyimpanan karbon dalam kurun waktu yang lama. Penyimpanan karbon di dalam tanah yang juga bisa dipakai sebagai bahan perbaikan tanah (amendment) perlu menjadi perhatian kita semua. Karbon sequestration adalah proses penangkapan gas $\mathrm{CO}_{2}$ dari atmosfir dan kemudian menyimpannya dalam waktu yang lama di dalam bumi agar supaya konsentrasi gas $\mathrm{CO}_{2} \mathrm{di}$ atmosfir tidak cepat meningkat. Siklus keluar masuknya karbon ke atmosfir ditunjukkan pada Gambar 2.

Ada beberapa route perpindahan karbon di alam, Gambar 2 menggambarkan siklus keluar masuknya karbon dari dan ke atmosfir yang berlangsung secara alami, yang bisa membuat konsentrasi gas $\mathrm{CO}_{2}$ di atmosfir berubah-ubah. Perpindahan karbon diantaranya adalah: ${ }^{[8]}$ 


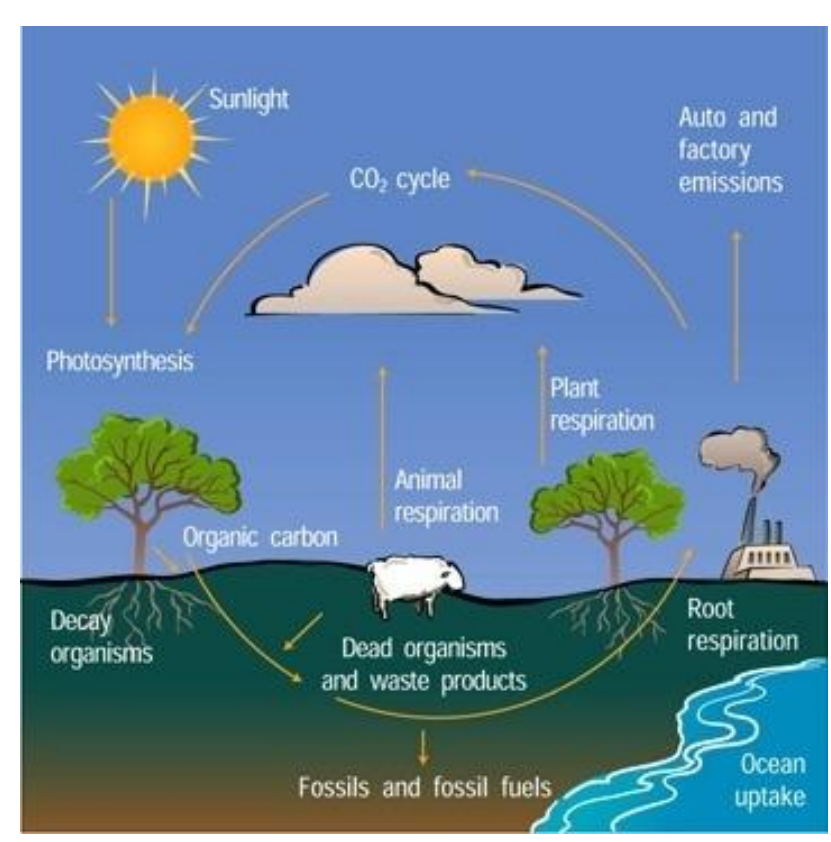

Gambar 2. Skema siklus gas $\mathrm{CO}_{2}$ di atmosfir ${ }^{[10]}$

1) Perpindahan karbon dari atmosfir ke tumbuhan. Karbon dalam bentuk karbon dioksida yang ada di atmosfir di serap oleh dedaunan dan bereaksi dengan air menjadi gula pada proses fotosintesis untuk pertumbuhannya. Reaksi fotosintesa seperti dibawah ini.

$$
\begin{aligned}
& 6 \mathrm{CO}_{2}+6 \mathrm{H}_{2} \mathrm{O} \rightarrow \mathrm{C}_{6} \mathrm{H}_{12} \mathrm{O}_{6}+6 \mathrm{O}_{2} \\
& \text { Karbondioksida Air Gula Oksigen }
\end{aligned}
$$

2) Perpindahan unsur karbon dari tumbuhan ke binatang. Tumbuhan dimakan oleh hewan yang akan menjadi daging dari hewan tersebut. Selanjutnya hewan tingkat rendah dimakan oleh hewan tingkat tinggi dan disitu terjadi perpindahan karbon dari spesies ke spesies lainnya.

3) Perpindahan karbon dari tumbuhan dan hewan ke tanah. Ketika tumbuhan dan hewan mati, keduanya akan jatuh ke tanah dan mengalami proses penguraian, atau terkubur dalam lapisan tanah dan menjadi fossil dalam jangka waktu yang lama.

4) Perpindahan karbon dari makhluk hidup ke atmosfir. Setiap yang hidup melakukan respirasi, yang mengeluarkan gas $\mathrm{CO}_{2} \mathrm{ke}$ atmosfir.

5) Perpindahan karbon dari fossil ke atmosfir. Material fossil ditambang kemudian dipakai sebagai bahan bakar, akan mengeluarkan gas hasil pembakaran berupa $\mathrm{CO}_{2}$ yang akan menyebar ke atmosfir. Pembakaran bahan bakar fossil ini ditengarai menyumbang gas $\mathrm{CO}_{2}$ terbesar dibandingkan dengan sumber-sumber GRK lainnya.

6) Perpindahan karbon dari atmosfir ke lautan. Lautan atau badan air lainnya menyerap gas $\mathrm{CO}_{2}$ dari udara menjadi $\mathrm{CO}_{2}$ terlarut.

7) Perpindahan karbon dari senyawa karbonat seperti batuan $\mathrm{CaCO}_{3}$ yang terurai menjadi oksida dan gas $\mathrm{CO}_{2}$. Sebagai contoh penguraian karbonat dari pabrik semen dan pengolahan kapur.

8) Gunung berapi mengeluarkan asap yang mengandung gas $\mathrm{CO}_{2}$.

9) Permukaan laut yang airnya makin panas akan mengakibatkan sebagian gas $\mathrm{CO}_{2}$ yang terlarut dalam air laut akan keluar ke atmosfir.

Hal tersebut di atas merupakan bentukbentuk perpindahan unsur karbon yang ada di alam ini. Dalam hubungan ini kita dapat mempengaruhi proses kesetimbangan $\mathrm{CO}_{2}$ di atmosfir supaya konsentrasinya tidak terus meningkat.

Penyimpanan biochar di dalam tanah mempunyai harapan yang baik sebagai penyimpanan karbon dalam kurun waktu yang cukup lama. Biochar di dalam tanah bisa bertahan sampai ribuan tahun. ${ }^{[1,12,13]}$ Ini merupakan daya simpan yang cukup lama. Di samping itu biochar di dalam tanah bisa berfungsi memperbaiki sifat tanah yang bisa menyuburkan tanah untuk keperluan pertanian. Biochar untuk memperbaiki sifat tanah harus melihat beberapa faktor: lama biochar bertahan dalam tanah; daya penghalang terhadap emisi gas rumah kaca; seberapa banyak biochar yang mesti ditambahkan kedalam tanah; berapa banyak biochar harus diproduksi agar bisa memenuhi jumlah yang diperlukan.

$\mathrm{Ho}^{[14]}$ menemukan bahwa biochar merupakan recalcitrant yang sukar teroksidasi. Endapan biochar di lautan stabil dalam waktu jutaan tahun, oleh karena itu biochar dengan kandungan karbon yang tinggi juga mempunyai 
umur yang panjang. Sampai saat ini keseimbangan antara gas $\mathrm{CO}_{2}$ yang masuk dan keluar atmosfir masih lebih banyak yang masuk. Oleh karena itu, konsentrasi gas $\mathrm{CO}_{2}$ di atmosfir akan mengalami kenaikan secara kontinyu, dan konsentrasi gas $\mathrm{CO}_{2}$ di atmosfir makin tinggi. Kemudian ada proses penggunaan gas $\mathrm{CO}_{2}$ oleh tanah, mikroba atau reaksi kimia di atmosfir yang bisa mengurangi konsentrasi gas $\mathrm{CO}_{2}$. Salah satu pengurangan gas $\mathrm{CO}_{2}$ dari atmosfir dalam jumlah besar adalah proses fotosintesis oleh tanaman yang memanfaatkan $\mathrm{CO}_{2}$ dari udara untuk direaksikan dengan air menjadi gula dan selanjutnya gula dirubah menjadi jaringan untuk tumbuhan tersebut. Setelah tumbuhan tersebut mati maka jaringan dari tumbuhan tersebut akan terurai oleh mikroorganisme kembali menjadi gas $\mathrm{CO}_{2}$ dan menyebar lagi ke atmosfir. Boleh dikatakan bahwa tumbuhan merupakan sistem penyimpan karbon sementara, proses penyimpanan ini dalam skala tahun sampai abad lamanya.

Ada pula proses penyimpanan karbon dalam waktu yang lebih lama sampai ribuan tahun, yaitu penyimpanan karbon dalam bentuk biochar di dalam tanah. Semua jaringan tumbuhan yang tidak digunakan sebaiknya dikonversi menjadi biochar atau arang dengan proses karbonisasi, setelah itu arang tersebut dipakai sebagai bahan perbaikan tanah, disitu karbon bisa tinggal dalam waktu ribuan tahun. ${ }^{[11,12,13]}$ Penyimpanan karbon di dalam tanah merupakan karbon-negatif yang perlu dilakukan oleh semua pihak agar bisa mengurangi konsentrasi gas $\mathrm{CO}_{2}$ di atmosfir.

\section{FUNGSI BIOCHAR}

\subsection{Biochar sebagai penyimpan karbon}

Karbon positif adalah proses penambahan karbon dalam $\mathrm{CO}_{2}$ ke atmosfir, sedangkan karbon negatif adalah proses pengurangan karbon dari atmosfir. Untuk menghambat terjadinya pemanasan global perlu diusahakan karbon negatif yang lebih intensif. ${ }^{[15]}$ Karbon negatif seperti penanaman tumbuh-tumbuhan akan meningkatkan proses fotosintesa. Biomasa yang dikonversi menjadi biochar kemudian dipakai untuk pemuliaan tanah pertanian. Supaya tidak banyak perubahan konsentrasi gas $\mathrm{CO}_{2}$ di atmosfir, maka harus ada keseimbangan antara karbon positif dan karbon negatif.

Setelah tanaman mati, biomasa yang ditinggalkan cepat terurai menjadi gas $\mathrm{CO}_{2}$ da kembali ke atmosfir baik melalui pembakaran atau peruraian anaerobik. Bila biomasa yang sudah mati dikonversi menjadi biochar dalam proses pirolisa atau korbonisasi hidrotermal, biochar yang diperoleh disimpan di dalam tanah sebagai penyubur tanah.

Biochar merupakan senyawa yang sangat stabil, sukar terurai oleh oksidasi mikroba di dalam tanah. ${ }^{[16]}$ Konversi biomasa menjadi biochar adalah transformasi dinamis yang berhubungan dengan karbon sequestration. Dalam proses karbonisasi biomasa setidaknya $50 \%$ karbon yang ada diubah menjadi karbon biochar. ${ }^{[17]}$ Proses pengomposan biomasa di dalam tanah akan mengeluarkan karbon dengan lambat, sampai kadar karbon tersisa sekitar 10 - 20\%, dimana kompos yang dihasilkan sudah dianggap stabil. Kompos ini akan berada di dalam tanah sekitar 5 sampai 10 tahun. Biochar berada di dalam tanah jauh lebih lama, dan fungsi biochar sebagai penyimpan nutrien lebih baik dibandingkan dengan kompos. ${ }^{[18]}$

Cara yang paling baik untuk menyimpan karbon adalah dengan memanfaatkan sisa-sisa tanaman yang berupa limbah biomasa untuk dikonversi menjadi biochar. Limbah pertanian dan kehutanan bila semuanya dikonversi menjadi biochar akan bisa membantu untuk melawan perubahan iklim global dengan beberapa cara:

1) Secara langsung menyimpan biochar dalam tanah sebagi karbon yang stabil.

2) Memindahkan bentuk karbon-positif dari energi fossil

3) Meningkatkan secara global Net Primary Production (NPP) dan kesuburan tanah

4) Mengurangi emisi gas nitrous oksida

Ada beberapa skenario dengan model yang lebih simple yang diusulkan oleh Amonette $\mathrm{e}^{[19]}$ dan Amonette ${ }^{[20]}$. Yaitu dihitung dari produksi biochar, ketersediaan biomasa 
dan lahan penyimpannya, kestabilan biochar ketika disimpan dalam tanah.

Stabilitas biochar di dalam tanah juga merupakan faktor yang penting. Biochar biasanya sangat stabil di dalam tanah. Stabilitas biochar tergantung dari temperatur prosesnya, misalnya proses pirolisa pada suhu $400^{\circ} \mathrm{C}$ lebih stabil dibandingkan dengan proses suhu 1000 ${ }^{\circ} \mathrm{C}$ pada oksidasi dengan ozon. ${ }^{[21]}$ Kadar aromatik pada biochar akan naik pada suhu pirolisa yang lebih tinggi dari $700{ }^{\circ} \mathrm{C} .{ }^{[22]}$

Untuk mempertahankan emisi karbon pada tahun 2055 setara dengan emisi karbon pada tahun 2015, perlu penyimpanan karbon sebesar 7 wedges (gigaton atau Pg) karbon. ${ }^{[23]}$ Namun, International Biochar Initiative (IBI), menargetkan pengurangan emisi karbon setiap tahunnya sebesar 1 gigaton atau "one wedge". ${ }^{[24]}$ Ada beberapa skenario yang bisa dipakai untuk memprediksi pengurangan emisi karbon di atmosfir, berdasarkan kelestarian ketersediaan biomasa dari global net primary production (NPP). Skenario pertama adalah sangat optimis, kedua optimis, ketiga moderat, dan keempat konservatif. Skenario konservatif menurut Krausmann, ${ }^{[25]}$ hanya tersedia $27 \%$ sisa-sisa biomasa dari hasil panen dan kehutanan yang bisa dipakai untuk biochar. Sedangkan skenario moderat dan optimis sekitar 50 sampai $80 \%$. Skenario sangat optimis adalah skenario optimis ditambah dengan potensi penambahan NPP sebesar $25 \%$, dan penurunan emisi $\mathrm{N}_{2} \mathrm{O}$ sebesar $50 \%$ dari pemakaian biochar di dalam tanah. ${ }^{[26]}$

Pada skenario sangat optimistik full wedge akan tercapai pada tahun 2040. Ketiga skenario diatas memprediksi bahwa pengaruh pengurangan emisi karbon sudah bisa dirasakan mulai tahun 2025. ${ }^{[21]}$ Hanya skenario yang optimis plus yang bisa mencapai 1 wedge pada tahun 2040. ${ }^{[24]}$ Ini merupakan usaha yang keras yang harus dilakukan untuk memproduksi biochar dalam jumlah yang besar untuk memenuhi skenario tersebut. Skenario pengurangan emisi karbon seperti ditunjukkan pada Gambar 3.

\section{Accreditation number : 540/AU1/P2MI LIPI/06/2013}

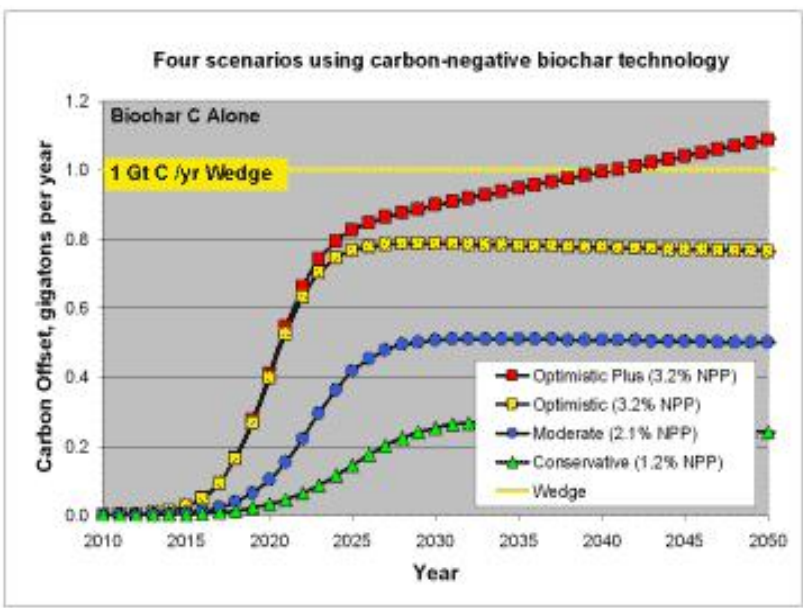

Gambar 3. Skenario pengurangan karbon ${ }^{[24]}$

\subsection{Biochar sebagai media perbaikan tanah pertanian}

Biochar merupakan karbon hitam yang diproduksi dari peruraian biomasa pada lingkungan yang tidak ada oksigennya seperti pirolisa atau gasifikasi. Biochar yang dihasilkan tidak seratus persen karbon, namun ada pengotornya seperti, tar, volatil, dan zat kimia lainnya seperti aromatik. Biochar yang baik untuk pemuliaan tanah adalah yang sangat sedikit pengotornya. Biochar berfungsi sebagai media penyimpan karbon dan penyubur tanah. $^{[13] \text {. }}$

Hal yang penting berkenaan dengan pemakaian biochar sebagai perbaikan sifat tanah (amendment), adalah (i) meningkatkan pertumbuhan; (ii) produksi biochar; (iii) penggunaan kembali limbah pertanian; (iv) produksi energi dari bahan baku terbarukan; (v) produksi biochar dari tanaman yang cepat tumbuh. ${ }^{[17]}$

Biomasa mengandung karbon sekitar 50\% yang dalam waktu singkat dapat dirubah menjadi biochar yang stabil dengan proses karbonisasi. ${ }^{[27]}$ Sebaliknya senyawa organik akan terdekomposisi di dalam tanah dengan mengeluarkan unsur karbon yang lebih lambat. Keluarnya unsur karbon berlangsung kurang dari 1 tahun untuk daerah tropis sehingga stabil di dalam tanah dalam bentuk kompos. ${ }^{\text {[28] }}$

\section{1) Meningkatkan pertumbuhan}

Berdasarkan penelitian di daerah tropis maupun subtropis biochar bisa meningkatkan 
pertumbuhan tanaman, mengurangi kehilangan nutrisi, menambah penahanan air, dan meningkatkan aktifitas mikroba. ${ }^{[29,30]}$ Total pertumbuhan biomasa tanaman bisa mencapai 189\% setelah pemakaian biochar sebanyak 23,2 ton setiap hektarnya. Produktifitas padi juga meningkat dengan penambahan biochar. [31] Penelitian mengindikasikan bahwa fiksasi nitrogen oleh mikroba meningkat setelah adanya pemakaian biochar. ${ }^{[32]}$ Penelitian juga memperlihatkan bahwa pertumbuhan tanaman makin baik setelah biochar menyatu dengan tanah. ${ }^{[33,34]}$

Pemakaian biochar untuk tanaman mempunyai efek yang kurang baik pada awalnya karena terjadinya perubahan $\mathrm{pH}$ pada tanah, banyaknya bahan yang volatil, dan perubahan konsentrasi nutrient secara mendadak. ${ }^{[35]}$ Disarankan agar pemberian biochar beberapa minggu sebelum memulai menanam, agar ada masa penyesuaian. Kualitas biochar yang baik meliputi kemampuan kapasitas adsorpsi, kapasitas penukaran kation, dan mengandung sedikit bahan yang mudah berpindah seperti tar, resin, dan zat volatil. Dengan berjalannya waktu kemampuan adsorpsi akan berkurang, sedangkan kapasitas penukaran kation bertambah. ${ }^{[33]}$

Jumlah biochar yang bisa ditambahkan kedalam tanah agar masih memberi manfaat adalah sebanyak 40\%. ${ }^{[36]}$ Sebagai contoh pada Amazonian dark earths, produktifitas tanahnya lebih baik dibandingkan dengan tanah yang tidak ada karbonnya. ${ }^{[37]}$ Tanah yang diberi biochar menunjukkan produktifitasnya naik walaupun penambahannya sampai $140 \mathrm{Mg}$ C/ha (Mega gram C/ha). ${ }^{[38]}$ Pada konsentrasi lebih tinggi lagi, sebesar $160 \mathrm{Mg} \mathrm{C} / \mathrm{ha}$ untuk tanaman kacang-kacangan tidak menunjukkan kenaikan yang berarti. ${ }^{[39]}$ Respon tanaman terhadap penambahan biochar menunjukkan penurunan jika diberi biochar dalam jumlah yang sangat tinggi. ${ }^{[39]}$

Biochar berguna untuk memperbaiki sifat-sifat tanah untuk meningkatkan kesuburan tanah ${ }^{[29]}$, terutama sebagai,

(1) Menaikan $\mathrm{pH}$ tanah. Arang mempunyai $\mathrm{pH}$ sekitar 9, ini sangat berguna bila $\mathrm{pH}$ tanah rendah, namun tidak baik bila $\mathrm{pH}$ tanah sudah tinggi. Bila $\mathrm{pH}$ tanah rendah maka akan terjadi netralisasi $\mathrm{pH}$ tanah, kalau $\mathrm{pH}$ tanah sudah tinggi maka $\mathrm{pH}$ tanah akan makin tinggi lagi.

(2) Penambahan nutrisi kedalam tanah. Abu arang banyak mengandung nutrisi yang dibutuhkan tanaman, namun penyediaan nutrisi ini untuk periode yang pendek saja. Setelah terjadi pembasuhan nutrisi oleh air, maka nutrisi di dalam arang akan berkurang dan akan habis dengan berjalannya waktu. Bila kadar nutrisi di dalam tanah tinggi maka arang menyerap kelebihan nutrisi dari tanah. Selanjutnya, bila kadar nutrisi tanah berkurang, maka nutrisi akan terlarut kedalam tanah kembali, semacam menjadi regulator pelepasan nutrisi.

(3) Permukaan biochar yang porous mampu menahan nutrisi yang ada di dalam tanah. Dengan berjalannya waktu nutrisi tersebut bisa digunakan oleh tanaman. Ini merupakan kegunaan biochar dalam jangka panjang. Biochar bisa bertahan di dalam tanah selama ribuan tahun.

(4) Biochar juga memperbaiki sifat-sifat fisika tanah. Biochar mempunyai densitas yang rendah dan sangat porous. Ini merupakan semacam spon yang bisa menyimpan air, yang bisa digunakan tanaman selama musim kering. Biochar juga bisa memperbaiki sifat penyerapan tanah terhadap air permukaan, dan mengurangi kekompakan tanah. Biochar bila ditambahkan pada tanah berpasir membantu menahan air, dan bila ditambahkan ke tanah yang berlempung maka akan memperbaiki aerasi tanah tersebut. ${ }^{[40,41]}$

(5) Karena biochar sangat porous maka merupakan tempat yang baik untuk tumbuhnya mikroba, seperti rhyzobia dan mycorrhizal yang merupakan mikroba penambat nitrogen yang sangat berguna untuk penyediaan nutrisi tanaman. ${ }^{[42]}$ Biochar dipandang sebagai bahan organik tanah sangat efektif untuk menahan nutrisi untuk persediaan tanaman. Biochar lebih stabil sebagai penyedia nutrisi 
dibandingkan dengan kompos atau kotoran binatang. ${ }^{\text {[3] }}$

Biochar sebagai soil amendment bisa meningkatkan produktifitas padi, memperbaiki $\mathrm{pH}$ tanah, manambah karbon tanah dan nitrogen total. ${ }^{[44]}$

\section{2) Potensi limbah pertanian dan hutan untuk produksi biochar}

Dalam sistem industri pertanian dan kehutanan akan dihasilkan limbah biomasa dengan jumlah yang sangat besar. ${ }^{[45]}$ Limbah biomasa tersusun oleh selulosa, hemi-selulosa dan lignin, dan lignin mempunyai prosentase karbon yang tinggi. Biomasa yang mempunyai kadar lignin yang tinggi baik untuk produksi biochar. ${ }^{[46]}$

Limbah biomasa seperti (i) sisa-sisa kegiatan hutan, sisa-sisa hasil penebangan dan kayu yang sudah mati; (ii) sisa-sisa pengolahan kayu, limbah penggergajian; (iii) sisa-sisa hasil panen; (iv) limbah rumah tangga. ${ }^{[47]}$ Perhitungan produksi biochar untuk mengurangi karbon $\mathrm{C}$ di atmosfir ditunjukkan pada Tabel 1.

Tabel 1. Perhitungan Karbon sequestration ${ }^{[48]}$

\begin{tabular}{|c|c|c|c|c|}
\hline $\begin{array}{c}\text { Jenis } \\
\text { limbah } \\
\text { biomasa }\end{array}$ & $\begin{array}{c}\text { Jumlah } \\
\text { (Juta } \\
\text { Ton) } \\
\text { pada } \\
\text { Tahun } \\
2009\end{array}$ & $\begin{array}{c}\text { Jumlah } \\
\text { biochar } \\
\text { (Juta } \\
\text { Ton) }\end{array}$ & $\begin{array}{c}\text { Karbon } \\
\text { yang } \\
\text { ada } \\
\text { pada } \\
\text { biochar } \\
\text { (Juta } \\
\text { Ton) }\end{array}$ & $\begin{array}{c}\text { Pengurangan } \\
\text { gas } \mathrm{CO}_{2} \\
\text { (Juta Ton) }\end{array}$ \\
\hline $\begin{array}{l}\text { Padi- } \\
\text { padian }\end{array}$ & 678 & 226,04 & 93,85 & 275,3 \\
\hline $\begin{array}{l}\text { Kacang- } \\
\text { kacangan }\end{array}$ & 29 & 12,249 & 8,574 & 25,15 \\
\hline $\begin{array}{l}\text { Kotoran } \\
\text { binatang }\end{array}$ & 900 & 330,21 & 108,9 & 319,64 \\
\hline $\begin{array}{l}\text { Limbah } \\
\text { yang } \\
\text { tidak } \\
\text { dibakar }\end{array}$ & 817 & 200,32 & 150,4 & 441,31 \\
\hline $\begin{array}{l}\text { Kulit dari } \\
\text { biji-bijian }\end{array}$ & 250 & 112,25 & 39,38 & 115,53 \\
\hline
\end{tabular}

\section{3) Produksi biochar dari limbah tanaman}

Sejak revolusi Industri pembuatan biochar lebih banyak dilakukan di negaranegara berkembang dibandingkan dengan negara maju. Negara-negara Industri sudah beralih ke energi fossil dan batubara, sedangkan negara berkembang masih mengandalkan energi biomasa terutama kayu. ${ }^{[49]}$ Pemakaian energi biomasa meningkatkan penebangan hutan secara masif dan menimbulkan polusi udara karena sistem pembakaran yang tidak efisien. Perbaikan teknologi pembuatan biochar dapat mengurangi polusi udara, seperti pemakaian teknologi karbonisasi hidrotermal yang lebih sedikit menghasilkan gas. ${ }^{[48]}$

Penggunaan lahan pertanian untuk ditanami tanaman yang cepat tumbuh yang dipakai sebagai bahan baku biochar mempunyai arti akan mengurangi emisi gas $\mathrm{CO}_{2}$ ke atmosfir. ${ }^{[50]}$ Tingginya ongkos produksi biochar menyebabkan produksi biochar tidak layak. Oleh karena itu untuk membuat produksi biochar bisa dilakukan dengan sistem terintegrasi antara lain dimanfaatkannya produk samping yang berupa bio-fuels, agar supaya usaha biochar bias layak. Varietas tanaman yang cepat dipanen dipakai sebagai bahan baku biochar seperti rumput-rumputan, ${ }^{[51]}$ dan tanaman obat. ${ }^{[52]}$ Kriteria yang harus dipenuhi tanaman untuk produksi biomasa adalah tingkat produksi biomasa per hektarnya.

Di samping itu makin banyak limbah biomasa dengan kadar air yang tinggi yang tidak bisa diproses dengan teknik pirolisa atau gasifikasi. Proses karbonisasi hidrotermal bisa memproses limbah dengan kadar air yang tinggi, tidak perlu proses pengeringan atau disebut wet pyrolysis. ${ }^{[53]}$ Karbonisasi hidrotermal diharapkan sebagai proses yang bisa diandalkan untuk limbah-limbah organik dengan kadar air yang tinggi yang biasanya menjadi pencemar, seperti limbah kotoran binatang, sewage sludge, biowaste, dan limbah industri pertanian. ${ }^{[54]}$ Dibandingkan dengan proses pirolisa, karbonisasi hidrotermal tidak perlu proses pengeringan yang banyak memerlukan energi. Hasil proses hidrotermal karbonisasi adalah karbon yang tersuspensi yang mudah dipisahkan dari larutannya. 
Proses karbonisasi hidrotermal sangat fleksibel dalam pemilihan bahan bakunya, semua jenis biomasa bisa diproses. ${ }^{[27]}$ Kotoran binatang, limbah kota, limbah pertanian, dan algae bisa diproses dengan karbonisasi hidrotermal. $^{[54]}$

Efisiensi konversi biomasa menjadi biochar sangat tergantung dari jenis biomasa yang diproses terutama komposisi selulosa, hemiselulosa dan ligninnya, namun tidak banyak pengaruh dari temperatur proses pirolisisnya (suhu antara $350-500{ }^{\circ} \mathrm{C}$ ). ${ }^{[16]}$ Struktur biochar yang dihasilkan masih menyerupai struktur biomasa bahan bakunya, dan merupakan material yang sangat porous dan mempunyai luas permukaan yang besar. ${ }^{[43]}$ Konversi biomasa dengan proses hidrotermal akan menghasilkan tiga fraksi yaitu, gas, organik terlarut dan padatan karbon ${ }^{[27]}$, seperti skema pada gambar 4.

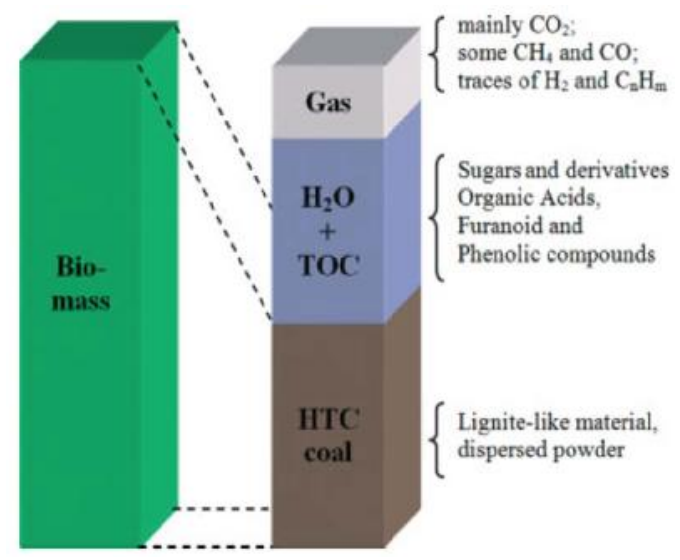

Gambar 4. Peruraian biomasa menjadi gas, cairan dan padatan ${ }^{[27]}$

\subsection{Arang biochar untuk mendukung lingkungan}

Beberapa studi tentang biochar menyatakan bahwa biochar bisa bertahan di dalam tanah selama berabad-abad sampai ribuan tahun. ${ }^{[13]}$ Ini karena biochar merupakan material yang sangat stabil tahan terhadap mikroba pengurai. Biochar lebih bersifat rekalsitran dibandingkan dengan bahan bakunya. ${ }^{[30]}$ Biochar sangat porous, sangat berguna untuk penyerapan unsur-unsur dalam tanah. Biochar berguna untuk lingkungan seperti:
1) Mengurangi pemakaian pupuk kimia. Terutama unsur nitrogen. Biochar mengabsorpsi ion-ion $\mathrm{NO}_{3}^{-}$dan $\mathrm{NH}_{4}{ }^{+}$lebih besar dari 0,6 mg/g biochar. ${ }^{[32]}$ Biochar akan mengurangi tingkat pembasuhan (leaching) dari mineral dan kation. ${ }^{55]}$

2) Mengurangi polusi nutrien yang ada dibadan-badan air, karena nutrisi tersebut bisa diserap oleh biochar yang mempunyai banyak pori-pori. Kegiatan pertanian sangat potensial menyebarkan polusi nutrien di badan-badan air seperti nitrogen dan pospor.

3) Biochar akan mengurangi produksi gas rumah kaca yang dihasilkan oleh tanah.

4) Biochar akan mengurangi mobilitas logamlogam berat dan pestisida di dalam tanah. Efek yang baik dari biochar terhadap tanah ini bisa dipakai sebagai alat untuk penanaman tumbuhan pada tanah yang terkontaminasi atau tanah yang telah terdegradasi. ${ }^{[4]}$

Pemakaian biochar di dalam tanah juga mampu mengurangi emisi gas rumah kaca lainnya. Penambahan biochar sebesar $20 \mathrm{~g} / \mathrm{kg}$ tanah dapat mengurangi emisi gas metan. ${ }^{[56]}$ Emisi nitrous oksida berkurang sampai 50\% pada pemakaian biochar pada tanaman kacangkacangan dan $80 \%$ pada tanaman rumputrumputan.

\section{KESIMPULAN}

Selama penambahan konsentrasi gas rumah kaca (GRK) berlangsung, maka pemanasan global akan terus terjadi. Pemanasan global akan mengakibatkan terjadinya perubahan iklim yang ekstrim. $\mathrm{CO}_{2}$ dari hasil pembakaran bahan bakar fossil berperan besar dalam meningkatkan konsentrasi gas $\mathrm{CO}_{2}$ di atmosfir. Sejak masa revolusi industri di Eropa, keseimbangan gas $\mathrm{CO}_{2}$ yang masuk dan keluar atmosfir menjadi terganggu karena konsentrasi $\mathrm{CO}_{2}$ di atmosfir meningkat. Untuk itu perlu usaha untuk mengurangi karbon $\mathrm{CO}_{2}$ dari atmosfir, misalnya dengan cara meyimpan biochar di dalam tanah dengan waktu yang cukup lama. Di dalam tanah, biochar dapat berfungsi sebagai 
penyubur tanah, sehingga bisa menjamin pertanian yang berkelanjutan. Menurut perkiraan, bila ada pengurangan karbon setara dengan 1 gigatons pertahun selama 40 tahun maka tingkat konsentrasi gas $\mathrm{CO}_{2}$ di atmosfir akan cenderung tetap. Untuk bisa mengurangi karbon dari atmosfir maka perlu diproduksi arang biochar dalam jumlah yang sangat banyak dengan menggunakan bahan baku sisasisa limbah organik atau biomasa. Hal ini perlu mendapat perhatian kita semua, bagaimana caranya membuat biochar dari sisa-sisa tanaman dalam jumlah yang sangat besar. Selama ini biochar diproduksi dengan proses pirolisa, yang juga menghasilkan gas $\mathrm{CO}_{2}$, yang langsung kembali ke atmosfir. Untuk mengurangi gas yang terjadi, proses karbonisasi hidrotermal merupakan proses yng lebih baik. Proses karbonisasi hidrotermal akan menghasilkan sedikit gas, zat organik terlarut dan padatan biochar. Di samping itu, proses karbonisasi hidrotermal bisa memproses berbagai jenis biomasa, seperti limbah biomasa dengan kadar air tinggi, kotoran binatang, dan limbah biogas yang tidak terurai.

\section{DAFTAR PUSTAKA}

[1] S. Connor. "Global warming: world already halfway towards threshold that could results in dangerous climate change, say scientists." Independent, vol. 10, Nov. 2015.

[2] J. Vidal. "Climat change will hit poor countries hardest, study shows." Global Development, Friday, 27 Sep. 2013.

[3] F. Harvey. "Climat change: How hot will it get in my lifetime?," in IPCC climte report: Human impact is ' unequivocal'. Intergovernmental panel on climate change (IPCC), Friday, Sep. 27, 2013.

[4] B. Kahn. "Climate change is messing with Earth's Axis. Climate Central, Apr. 11, 2016.

[5] Effects of changing the Carbon Cycle: Feature article. http://earthobservatory.nasa.gov/features/ carbon cycle/page 5.php/. (diakses tgl. 14 Agt. 2014.

[6] P. Falkowski, R.J. Scholes, E. Boyle, J. Canadell, D. Canfield, J. Elser, N. Gruber, K. Hibbard, P. Hogberg, S. Linder, F.T. Mackenzie, B. Moore, T. Pedersen, Y. Rosenthal, S. Seitzinger, V. Smetacek, W. Steffen. "The Global Carbon Cycle: A Test of Our Knowledge of Earth as A System." Science, vol. 290 (5490), pp. 291-296, 2000.

[7] Anon1. Carbon and Climate. http://carboncycle.aos.wisc.edu/ (diakses tgl. 11 Agt. 2014).

[8] J.M. Shepherd. "Carbon, climate change, and controversy." Animal Frontiers, vol.1 (1), pp. 5-13, 2011.

[9] P. Friedlingstein, R.A. Hougton, G. Marland, I. Hacker, T.A. Roden, T.L. Conway, G. Canadell, M.R. Raunach, P. Ciais, C. Le Quere. "Update on $\mathrm{CO}_{2}$ emissions." Nature Geoscience. Doi: 10.1038/ngeo1022, 2010.

[10] R. Johnson. "The Carbon Cycle." Window to the universe, 7 Nov. 2010.

[11] E. Vaegele. "ACR accepting comments on biochar methodology for carbon credits". Biomass, Oct 02, 2013.

[12] B. Titiz and R. Sanford. "Soil Charcoal in Old-Growth Rain Foresta from Sea Level to the Continental Divide." Biotropica, vol. 39, pp. 673-682, 2007.

[13] S.P. Sohi, E. Krull, E. Lopez-Capel, and R. Bol. A Review of Biochar and Its Use and Function in Soil. Advances in Agronomi, vol. 105, Burlington: Academic Press, pp. 47-82, 2010.

[14] M.W. Ho. (2010). Beware the biochar initiative. /global-warming/beware the biochar initiative- The Permaculture Research In......./ (diakses 06 Mei 2016).

[15] N.P. Gurwick, C. Kelly and P. Elias. "The Scientific Basis for Biochar as A Climate Change Mitigation Strategy: Does it 
Measure Up?. Union of Concerned Scientists, pp. 1-15. Sep. 2012.

[16] E.R. Graber. "Biochar for $21^{\text {st }}$ century challenges: Carbon sink, energy source and soil conditioner." Conf.Proc.,Dahlia Gredinger Int. Symp. Haifa, May 2009.

[17] S.K. Hoekman, A. Broch, C. Robbins, B. Zielenska and L. Felix. "Hydrothermal carbonization (HTC) of selected woody and herbaneous biomass feedstocks." Biomass Conv. Bioref, vol. 3 (2), pp. 113126, 2013.

[18] S.V. Praba, et al. "A Study of the fertlity and carbon sequestration potential of rice soil with respect to the application of biochar and selected amendments." Annals of Environmental Science, vol. 7, pp. 17-30, 2013.

[19] J.E. Amonette, J.C. Lehmann, and S. Joseph. "Terretrial Carbon Sequestration with biochar: A preliminary Assessment of its Global potential," presented at American Geophysical Union, San Francisco, CA, Dec. 13, 2007.

[20] J.E. Amonette, J.C. Lehmann, and S. Joseph. "Biomass carbonization: The dark side of terretrial Carbon Sequestration. Poster presented at "Climate Change: Science and Solutions", $8^{\text {th }}$ National Conf. on Science, Policy and the Environment, Washington, DC, Jan. 16, 2008.

[21] K. Kawamoto, K. Ishimaru, and Y. Imamura. "Reactivity of wood charcoal with ozone." J. Wood Science, vol. 51, pp. 66-72, 2005.

[22] U. Hamer, B. Marschner, S. Brodowski, and W. Amelung. "Interative priming of black carbon and glucose meniralization." Organic Geochemistry, vol. 35, pp. 823830, 2004.

[23] S. Pacala and R. Socolow. "Stabilization wedges: Solving the climate problem for the next 50 years with current technologies." Science, vol. 205, pp. 968972, 2004.
[24] Anon2. How much carbon Can Biochar System Offset- and When?. International Biochar Initiative.

www.biochar-international.org. (diakses tanggal 28 Okt. 2014).

[25] F. Krausmann, K.H. Erb, S. Gingrich, C. Lauk, and H. Haberl. "Global patterns of socioeconomic biomass flows in the year 2000: A comprehensive assessment of supply, consumption and constraints." Ecological Economics, vol. 65, pp. 471487, 2008.

[26] P.J. Crutzen, A.R. Mosier, K.A. Smith, and $\mathrm{W}$. Winiwarter. " $\mathrm{N}_{2} \mathrm{O}$ release from agro-biofuel production negates global warming reduction by replacing fossil fuels." Atmospheric Chemistry and Physics Discussions, vol. 7, pp. 1119111205, 2007.

[27] A. Funke and F. Ziegler. "Hydrothermal carbonization of biomass: a summary and discussion of chemical mechanisms for process engineering." S.1: Biofuels. Bioprod. Bioref, vol. 4, pp. 160-177, 2010.

[28] N. Ameloot, E.R. Graber, F.G.A. Verheijen, and S. De Neve. "Interactions between biochar Stability and Soil Organisms: review and research needs." European Journal of Soil Science, vol. 64, pp. 379-390, 2013. Doi: 10.111/ejess. 12064.

[29] L. Macdonald. "Biochar overview: Biochar as a soil amendment in agriculture. CSIRO, Australia, pp. 1-4, 2013.

[30] S. Trumbore. "Age of Soil organic matter and Soil respiration: Radiocarbon constrains on Belowground C Dynamics." Ecological Applications, vol. 10 (2), pp. 399-411, 2000.

[31] A. Zhang, et al. "Effects of biochar amendment on soil quality, crop yield and green house gas emission in a chinese rice paddy: A field study of 2 consecutive rice growing cycles." Field crops Research, vol. 127, pp. 153-160, 2012. 
[32] T.J. Clough, et al. "A Review of biochar and Soil Nitrogen Dynamics." Agronomy, vol. 3, pp. 275-293, 2013.

[33] P. Rastanlimar, U. Prawiro, dan E. Turmudi. "Pemanfaatan biochar untuk perbaikan Kualitas tanah dengan Indikator Tanaman Jagung hibrida dan Padi Gogo pada sistem lahan tebang dan bakar." NATURALIS, vol.1 (3), pp. $179-188$, 2012).

[34] Major, J., M. Rondon, D. Molina, S.J. Riha, and J. Lehmann. "Maize yield and nutrition after 4 years of doing biochar application to a colombian savanna oxisol." Plant and Soil, vol. 333, pp. 117128, 2010.

[35] T. McClellan, J. Deenik, G. Uehara, and M. Antal. "Effects of flashed carbonized macadamia nutshell charcoal on plant growth and soil chemical properties," ASA-CSSA-SSA international Annual Meetings, New Orlens, Louisiana, USA, Nov. 6, 2007.

[36] B. Glasner, L. Haumaier, G. Guggenberger, and W. Zech. "The Terra P)reta phenomena - A model for sustainable agriculture in the humid tropics." Naturwissenschaften, vol. 88, pp. 37-41, 2001.

[37] J. Lehmann, D.C. Kern, L.A. German, J. McCann, G.C. Martins, and A. Moreira. Soil fertility and Production Potential. Amazonian Dark Eraths; Origin, Properties, Management, pp. 105-124, Dordrecht, Kluwer Academic Pub., 2003.

[38] J. Lehmann and M. Rondon. Biochar soil management on highly-weathered soils in the humid tropics. Biological Approaches to Sustainable Soil Systems. Boca Raton, CRC Press, 2005.

[39] M. Rondon, J. Lehmann, J. Ramirez, and M.P. Hurtado. "Biologial nitrogen fixation by common beans (Phaseoulus vulgaris) increases with charcoal additions to soils." In Integrated Soil Fertility Management in the Tropics, Annual Report of the TSBF Institute, CIAT, Cali, Colombia, pp. 58-60, 2004.

\section{Accreditation number : 540/AU1/P2MI LIPI/06/2013}

[40] E.R. Graber. "Biochar for $21^{\text {st }}$ Century Challenges: Carbon sink, energy source and soil conditioner." Conference Proceedings, Dahlia Gredinger International Symphosium, Haifa, pp. 1-8, May 2009.

[41] L. Ouyang, F. Wang, J. Tang, L. Yu, and R. Zhang. "Effects of biochar amendment on soil aggregates and hydraulic properties." J Soil Science and Plant Nutrition, vol. 13 (4), pp. 991- 1002, 2013.

[42] J. Major. Biochar: a new soil management tool for farmers and gardeners, 2011.

[43] International Biochar Initiative. Appalachian Sustainable Development, Report, pp. 1-12.

[44] K.Y. Chan, L.V. Zwieten, I. Meszaros, A. Downie, and S. Joseph. "Agronomic values of greenwaste biochar as a soil amendment." Australian J. Soil Res, vol. 45, pp. 629-634, 2007.

[45] A. Zhang, R. Bian, G. Pan, L. Cui, Q. Husaain, L. Li, J. Zheng, X. Zhang, X. Han, and X.D. Yu. "Effects of biochar amendment on soil quality, crop yield and greenhouse gas emission in a Chinese rice padday: A field study of 2 consecutive rice growing cycles." Field Crops Research, vol. 127, pp. 153-160, 2012.

[46] R. Bailis, M. Ezzati, and D.M. Kammen. "Mortality and greenhouse gas impacts of biomass and petroleum energy futures in Africa." Science, vol. 208, pp. 98- 103, 2005.

[47] M.E. Walsh, R.L. Perlack, A. Turhollow, D.T. Ugarte, D.A. Becker, R.L. Graham, S.E. Slinksy, and D.E. Ray. Biomass Feedstock Available in the United State. State Level Analysis, Oak Ridge National Laboratory: Oak Ridge, TN, 1999.

[48] E. Maftu'ah dan D. Nursyamsi. "Potensi berbagai bahan organik rawa sebagai sumber biochar." Pros. Sem. Nas. Masy. Biodiv. Indonesia, vol. 1 (4), pp. 776781, 2015. 
[49] A. Stoyle. Biochar production for carbon sequestration, bachelor thesis of science in Chemical Engineering. Shanghai Jiao Tong University, China, 2011.

[50] A.A. Ernsting. A climate smart solution. In Climate Change and Agriculture.. VISUELL, Werbung und Kommunikation, Aachen, Germany, 2011.

[51] W. Seifritz. "Should we store carbon in charcoal?" Int. J. of hydrogen Energy, vol. 18, pp. 405-407, 1993.

[52] J.C. Clifton-Brown, P.F. Stampfl, M.B. Jones. "Miscanthus biomass production for energy in Europe and its potential contribution to decreasing fossil fuel carbon emissions." Global Change Biology, vol. 10, pp. 509-518, 2004.

[53] J. Kamm. "A new class of plants for a biofuel feedstock energy crop." Applied Biochemistry and Biotechnology. Vol 113, pp. 55-70, 2004.

[54] H.G. Ramke, et al. Hydrothermal carbonization of organic waste. Sardina: Twelfth International Waste Management and Landfill Symposium, 2009.

[55] J.A. Libra, et al. "Hydrothermal carbonization of biomass residuals: a comparative review of the chemistry processes and application of wet and dry pyrolysis." Biofuels, vol. 2 (1), pp. 89124.

[56] M.P. Sika. Effect of biochar on chemistry, nutrient uptake and fertilizer mobility in sandy soil, master thesis in Agriculture, The University of Stellbosch, South Africa, 2012.

[57] M. Rondon, J. Ramirez, J. Lehmann. "Charcoal additions reduce net emissions of greenhouse gases to the atmosphere." In Procedings of the $3^{\text {rd }}$ USDA Symposium on Greenhouse Gases and Carbon Sequestration, Baltimore, USA, pp. 208, Mar. 21-24, 2005. 